\title{
1. Evaluating control of nutrient flow in an estuarine nitrogen cycle through
}

\section{comparative network analysis}

\author{
David E. Hines ${ }^{\mathrm{a}, \mathrm{b}, *}$, Pawandeep Singh ${ }^{\mathrm{c}}$, Stuart R. Borrett ${ }^{\mathrm{a}, \mathrm{d}}$ \\ ${ }^{a}$ Department of Biology \&S Marine Biology, University of North Carolina Wilmington, 601 S. College Rd., Wilmington, \\ $28403 N C, U S A$ \\ ${ }^{b}$ Center for Marine Science, University of North Carolina Wilmington \\ ${ }^{c}$ Visva-Bharati University, Santiniketan, India \\ ${ }^{d}$ Duke Network Analysis Center, Social Science Research Institute, Duke University, Durham, 27708 NC, USA
}

\section{Abstract}

Ecologists, ecosystem managers and ecological engineers often seek to identify which components of an ecosystem are most important to its functioning. Ecosystem Network Analyses (ENA) can be used as a tool to address this challenge while taking into consideration the complex direct and indirect interactions that occur in natural systems. One way that ENA can inform researchers and policy makers is through a broad array of centrality metrics, which quantitatively describe the relative importance of each ecosystem component. Control analysis, a type of ENA, identifies which ecosystem members regulate the organization and distribution of energy matter once it enters the ecosystem. We applied two subroutines of control analysis, system control and control difference, to two nitrogen cycling models constructed at sites with different salinity regimes (one oligohaline and one polyhaline) in the Cape Fear River Estuary, NC, USA. We compared the analysis results for these two models to infer how salinity and seawater intrusion might change the control relationships, and therefore functional importance, of nitrogen cycling components. We assert that system control analysis can be used as a centrality metric for evaluating the relative function of ecosystem components, and we compared the system control results to three centrality measures that are established in the literature. Spearmans' $\rho$ tests for correlation indicated no significant relationship between the system control results and selected centrality measures, highlighting the ability of this tool to provide novel information. The system control results indicated that sedimentary nitrate and nitrite were most important for regulating the distribution of nitrogen at both sites, highlighting the centrality of nitrate and nitrite in estuarine nitrogen cycling. However, the control difference analysis, which has finer resolution than system control, indicated that the ammonium pool regulated the movement of nitrogen through the nitrate and nitrite pools at the oligohaline site, while the opposite was observed at the polyhaline site. This reversal of control relationship suggests that seawater intrusion may alter which ecosystem components regulate the distribution of energy matter for reactive nitrogen species in estuaries. This work identifies the 
utility and uniqueness of system control as a centrality measure, provides an example of an application of control analysis to identify key ecosystem components, and identifies a potentially important difference in the roles of nitrogen cycling components at two sites.

Keywords: Ecosystem Network Analysis, Network ecology, Control analysis, Nitrogen cycle, Uncertainty analysis, Process coupling, Seawater intrusion, Centrality

\section{Introduction}

Ecologists, policy makers, and ecological engineers are interested in the management, maintenance, and restoration of estuaries because of the economic and environmental services that these ecosystems provide (Costanza et al., 1997; Thom, 1997; Zedler and Kercher, 2005; Boesch, 2006; Paerl, 2006). In estuarine ecosystems, nitrogen $(\mathrm{N})$ availability often limits primary production (Ryther and Dunstan, 1971; Howarth and Marino, 2006) and an excess of $\mathrm{N}$ containing compounds can lead to eutrophication that can result in algal blooms, hypoxia, and fish kills (Burkholder et al., 1997; Anderson et al., 2002). The negative effect that eutrophication can have on estuarine ecosystem services has contributed to sustained interest in quantifying, understanding, and ultimately managing the role of nutrients in these environments (Nixon, 1995; Seitzinger and Sanders, 1997; Cloern, 2001; Whitall et al., 2004; Kemp et al., 2005). Furthermore, concern over health risks from cyanobacterial toxins that are sometimes produced in eutrophication events has fueled interest in management strategies for $\mathrm{N}$ in estuaries (Codd, 2000).

Despite the need for well informed management policies in estuarine ecosystems, the majority of studies evaluating the estuarine $\mathrm{N}$ cycle incorporate only a fraction of the ecosystem's functioning because the complexity of the interactions among different $\mathrm{N}$ species makes a whole-ecosystem approach difficult to achieve (Boynton et al., 2008). $\mathrm{N}$ is present in estuaries as dissolved and particulate organic matter, as well as in inorganic forms including ammonium $\left(\mathrm{NH}_{4}^{+}\right)$, nitrite $\left(\mathrm{NO}_{2}^{-}\right)$, nitrate $\left(\mathrm{NO}_{3}^{-}\right)$, and di-nitrogen gas

$\left(\mathrm{N}_{2}\right)$. The abundance of these different forms of inorganic $\mathrm{N}$ can have important implications for primary production in these ecosystems (Fisher et al., 1988; Anderson et al., 2002). For example, Paerl (2006) found that both the quantity and form of $\mathrm{N}$ compounds were closely linked to duration and species composition of phytoplankton blooms in the Neuse River Estuary, NC.

The diversity of $\mathrm{N}$ forms present in estuaries, along with the implications of these substrates for biological activity, make achieving a whole-ecosystem analysis of the estuarine $\mathrm{N}$ cycle an essential step for informing

\footnotetext{
*Corresponding author. Tel. 910.962.3000; fax: 910.962.4066

Email addresses: deh9951@uncw.edu (David E. Hines), pawan.s@live.co.uk (Pawandeep Singh), borretts@uncw.edu (Stuart R. Borrett)
} 
management polices for estuaries (Boynton et al., 2008). The $\mathrm{N}$ species in estuaries are influenced by allochthonous $\mathrm{N}$ inputs from outside of the ecosystem, chemical factors such as ion content, physical factors such as flushing time, and the biological communities that rely on these nutrients (Rudek et al., 1991; Caraco et al., 1998; Cabrita et al., 1999). Microbial organisms in estuaries convert N between different forms as part of metabolic redox reactions, creating a complex biogeochemical cycle that regulates the flow of $\mathrm{N}$ through these ecosystems. For example, the process of nitrification oxidizes $\mathrm{NH}_{4}^{+}$to $\mathrm{NO}_{3}^{-}$to provide electrons for organic carbon fixation, while dissimilatory nitrate reduction to ammonium (DNRA) reduces $\mathrm{NO}_{3}^{-}$to $\mathrm{NH}_{4}^{+}$to oxidate organic carbon under anaerobic conditions (Canfield et al., 2010). These processes recycle $\mathrm{N}$ within an estuary by converting it from one biologically available form to another, while other microbial processes such as denitrification (conversion of $\mathrm{NO}_{3}^{-}$to $\mathrm{N}_{2}$ ) and anaerobic ammonium oxidation (anammox; combination of $\mathrm{NH}_{4}^{+}$and $\mathrm{NO}_{2}^{-}$to produce $\mathrm{N}_{2}$ ) effectively remove $\mathrm{N}$ from estuaries. The $\mathrm{N}_{2}$ gas produced by these processes is relatively bio-unavailable due to low $\mathrm{N}$ fixation rates in these ecosystems, and therefore is removed to the atmosphere (Howarth et al., 1988; Bovnton and Kemp, 2008). Detailed reviews of the estuarine N cycle can be found in Boynton and Kemp (2008), Jove and Anderson (2008), and Canfield et al. (2010).

The microbial communities that conduct these $\mathrm{N}$ transformation processes are susceptible to changes in environmental conditions. For example, seawater intrusion, which can occur gradually as a result of climate change (Day et al., 2005) or more rapidly as a result of engineering projects including dredging (Jang et al., 2012), may alter which organisms and processes are dominant in an estuarine N cycle. Bernhard et al. (2005, 2007) found that diversity and functionality of ammonia-oxidizing bacteria differed along an estuarine salinity gradient. Furthermore, some N cycling reactions, such as nitrification, are inhibited by high levels of salinity (Joye and Hollibaugh, 1995), while other reactions, such as DNRA, can be enhanced by the same conditions (Giblin et al., 2010, 2013). As seawater intrusion from dredging and climate change progresses (Hackney and Yelverton, 1990; Zhang et al., 2012), it is unclear how these changes in water chemistry will effect the microbial communities involved in the $\mathrm{N}$ cycle or the interactions among $\mathrm{N}$ cycling processes (Santoro, 2010). Therefore, understanding how these projected environmental changes will alter the estuarine $\mathrm{N}$ cycle from a whole-ecosystem perspective is a crucial goal for managers and policy makers.

As a step toward managing ecosystems, it is useful to identify which components of an ecosystem are most important to its functioning (Mills et al., 1993; Jordán et al., 2006; Sutherland et al., 2006; Crowder and Norse, 2008). Identifying the components, both biotic and abiotic, that regulate ecosystem functioning provides information on how to appropriately apply ecological data to implement management policies and monitor 
environmental responses (Ehrlich and Moonev, 1983; Christensen et al., 1996; Kremen, 2005). For example, Bengtsson (1998) found that understanding which members and relationships in an ecosystem contribute to its function can be more useful to managers than measures focused on community diversity. However, identifying which components are most important from a whole-ecosystem perspective can be a difficult task because of the complex nature of the interactions among ecosystem members (Walker, 1992; Hooper et al., 2005; Levin and Lubchenco, 2008).

As one tool to evaluate ecosystems from a whole-ecosystem perspective, ecologists have developed a set of computational algorithms called Ecosystem Network Analysis (ENA; Fath and Patten, 1999; Ulanowicz, 2004; Schramski et al., 2011). ENA, part of the rapidly growing field of network ecology (Borrett et al., 2014), traces the movement of energy-matter through network models that explicitly include both the direct and indirect interactions among all ecosystem components (Fath et al., 2007; Schramski et al., 2011). These networks represent steady-state budgets of thermodynamically conserved material as it moves through the different biotic and abiotic resource pools within an ecosystem, enabling ENA techniques to provide the whole-system measures of ecosystem relationships and functioning that are commonly lacking in studies of complex systems (Boynton et al., 2008; Patten, 2013).

Several ENA tools, which are often adapted from the social and economic sciences (Hannon, 1973; Wasserman and Faust, 1994; Borgatti, 2005; Estrada, 2010), have been used to define and identify key components in ecosystems (Jordán et al., 2007; Estrada and Bodin, 2008; Borrett, 2013). These algorithms compute measures of centrality for each component in an ecosystem network. Centrality metrics provide information on the ability of each component of an ecosystem network to influence the other network components, and thus quantify the importance of each piece of an ecosystem network to the overall functioning of the system (Estrada, 2007). Some centrality metrics consider only which connections are present between network components, while others take into account the magnitudes of these network connections (Borgatti and Everett, 2006).

ENA produces centrality metrics that range from local to global in scope (Estrada, 2010; Borrett, 2013). For example, one type of centrality called degree centrality provides a local measure of importance by quantifying the number of direct relationships each ecosystem member has with other ecosystem components (Freeman, 1979; Wasserman and Faust, 1994). Another type of centrality called eigenvector centrality, however, provides a global measure of importance by quantifying the equilibrium number of pathways for material moving through each component in an ecosystem network, considering all direct and indirect interaction (Bonacich, 1972, 1987, 2007). Global centrality measures can be particularly useful for understanding 
the roles of different components in ecosystem networks.

Another global analysis in ENA called control analysis identifies the relative influence of each network component on the movement of energy-matter through a network (Patten and Auble, 1981; Fath, 2004; Schramski et al., 2006). This tool can be useful to ecosystem managers because it identifies which components regulate the flow of energy-matter through an ecosystem network, but is rarely used because of heavy data requirements and difficulty interpreting the degree of uncertainty in the results of steady-state models. More specifically, this analysis allows researchers to quantify the ability of each network component to regulate flow in the context of an energy or nutrient ecosystem budget. In this work, we provide an example of an application and interpretation of the ENA control analysis described in Schramski et al. (2006) to a case study of two N cycling ecosystem networks constructed at locations with different influences from salinity in the Cape Fear River Estuary (CFRE), NC, USA. Previous work on this system has shown that the pathways contributing to $\mathrm{N}_{2}$ production differ between these networks such that direct $\mathrm{N}_{2}$ production is favored to coupled $\mathrm{N}_{2}$ production at the site with greater influence from seawater, and therefore suggests that the components regulating the flow of $\mathrm{N}$ through these networks may also be different (Hines et al., 2015). We combine the control analysis with an uncertainty analysis based on linear inverse modeling (Kones et al., 2009) to demonstrate how this technique can be used to inform management and policy decisions. We 1) show that control analysis results for each network component provide a global measure of centrality that provides different information from established centrality measures, 2) compared the control analysis results for networks at sites with different exposure to salinity, using the uncertainty analysis to test the hypothesis that the differences in the $\mathrm{N}_{2}$ production pathways observed in these networks (Hines et al., 2015) will result in differences in the components that regulate the flow of $\mathrm{N}$ at these sites, and 3) highlighted ecologically relevant differences in the relationships between different $\mathrm{N}$ pools at these sites that should be considered when making management decisions.

\section{Materials and Methods}

We conducted control analysis on two previously published $\mathrm{N}$ cycling network models from sites in the CFRE with different influences from seawater (Hines et al., 2012, 2015). We then compared these results with the results of other centrality measures from ENA to demonstrate the utility of control analysis. Next, we applied an uncertainty analysis to assess the significance of the differences between the sites, and finally, we used a space-for-time substitution to generate predictions about how anticipated seawater intrusion may alter the estuarine $\mathrm{N}$ cycle. 


\subsection{Network Models}

The networks used in this case study were constructed at oligohaline and polyhaline sites in the CFRE. The oligohaline network was constructed by Hines et al. (2012) to represent the average conditions in a reach

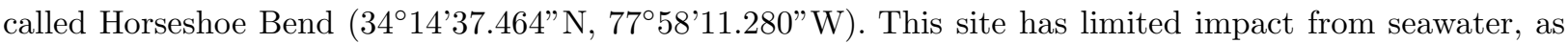
salinity routinely ranges from 0.1 to $5.0 \mathrm{ppt}$ (Mallin et al., 2009, 2010). The polyhaline network, constructed by Hines et al. (2015), represented a section of river at Channel Marker $35\left(34^{\circ} 2^{\prime} 2.688^{\prime \prime} \mathrm{N}, 77^{\circ} 56^{\prime} 21.948^{\prime}\right.$ 'W), which regularly experiences salinity greater that 10 ppt (Mallin et al., 2009, 2010). A comparative description of the physical characteristics, environmental parameters and network models at each of these sites can be found in Hines et al. (2015), and detailed descriptions of the environmental conditions throughout this estuary can be found in Mallin et al. (2009, 2010).

Both the oligohaline and polyhaline networks had identical geometry consisting of nodes representing four species of $\mathrm{N}$ : ammonium $\left(\mathrm{NH}_{4}^{+}\right)$, nitrate-nitrite $\left(\mathrm{NO}_{x}^{-}\right)$, microbes $(\mathrm{M})$, and organic nitrogen (ON). Nodes for these four $\mathrm{N}$ pools were duplicated in the water column (W-) and sediment ( $\mathrm{S}-)$, respectively, for a total of eight nodes at each site (Fig. 1). The nodes in each network were connected to each other by 23 fluxes (edges) that represent internal N cycling processes, and to the external environment by 19 boundary fluxes (Fig. 11). Although some of these fluxes were associated with anaerobic processes such as denitrification and others were associated with aerobic processes such a nitrification, microenvironments within the sediment allow for all of these processes to occur simultaneously within the modeled area (Revsbech et al., 2005). The magnitudes of each of the $\mathrm{N}$ fluxes connecting the network nodes were parameterized by a combination of empirical measurements (11 fluxes, 26\%), literature values (22 fluxes, 51\%), and mass balance estimations (10 fluxes, 23\%) at each site, and thus differed between the two networks. For example, the flux representing nitrification was present in both models, but it was larger in the oligohaline network $\left(144.0 \mathrm{nmol} \mathrm{N} \mathrm{cm}^{-3} \mathrm{~d}^{-1}\right)$ than the polyhaline network $\left(77.5 \mathrm{nmol} \mathrm{N} \mathrm{cm} \mathrm{n}^{-3} \mathrm{~d}^{-1}\right)$. A justification for the structure of these network models can be found in Hines et al. (2012), and complete information about the source of each parameter, the uncertainties associated with these values, and a detailed comparison of these sites is presented in Hines et al. (2015). Previous analyses on these networks indicated that, while the total amount of $\mathrm{N}$ moving through the oligohaline network is greater than the polyhaline network, no significant difference in cycling or $\mathrm{N}$ removal capacity could be detected between the sites. However, significantly more $\mathrm{N}_{2}$ production was associated with coupling between nitrification and denitrification in the oligohaline network, suggesting that the N cycle may not functions in the same way at these sites (Hines et al., 2015). 


\subsection{Control analysis}

The control analysis used in this work was formulated by Schramski et al. (2006) to further develop the techniques presented in Patten and Auble (1981) and Fath (2004). This type of control analysis uses the input and output flow environ concepts (Patten and Auble, 1981; Patten, 1982) to quantify the effect of one network component on another from a global perspective. Environs are sub-network partitions that represent of all of the flows involved in the input or output directions from a given node, without changing the network topology. Ecosystem control analysis examines the environ contributions of every node in an ecosystem network to every other node by computing the flow to and from each node, relative to the total amount of material moving through each node (Schramski et al., 2006). This comparison, when applied to all possible node combinations, results in the control difference matrix $\mathbf{C D}=\left[c d_{i j}\right]$, which shows the control relationships between each pair of nodes in a network of $n$ nodes. Positive values of $c d_{i j}$ indicate that node $i$ (row node) controls the flow of matter through node $j$ (column node), while negative values indicate the opposite relationship. Nodes that exert positive control on another node contribute more energy-matter to the other node than they receive, and therefore contribute to the regulation of that compartment. We used this system based comparison to evaluate the ability of different pools of $\mathrm{N}$ in the CFRE models to influence other pools of $\mathrm{N}$ in the networks.

The representation of each node's control provided by $\mathbf{C D}$ can be used to evaluate the control of each network component on the system as a whole. The values of the CD matrices are additive, as they are referenced to the same system. Therefore, the rows of the CD matrix were used to obtain the system control vector $\overrightarrow{s c}=s c_{i}$. We used the system control values to determine the system-wide control relationship for each network node. As with the CD matrix, positive $s c_{i}$ values indicated that node $i$ exerted control on the rest of the system, while negative values indicated that node $i$ was controlled by the rest of the system. When summed, the positive and negative values of $s c_{i}$ cancel such that $\sum_{i=1}^{n} s c_{i}=0$, indicating total system balance (Schramski et al., 2006).

\subsection{Centrality comparison}

We examined three established centrality measures from the literature to showcase the differences among these techniques and highlight the utility of system control $(\overrightarrow{s c})$ as a centrality measure for identifying key ecosystem components. Specifically, we calculated the average eigenvector centrality of the adjacency matrix, average environ centrality, and throughflow centrality for each ecosystem component. Average eigenvector centrality is a dimensionless measure of the equilibrium number of possible pathways for material 
to move through each member in a network (Bonacich, 1972, 1987). Average environ centrality shows the relative contribution of each network component to the movement of energy-matter through the ecosystem (Fann and Borrett, 2012). Throughflow centrality provides a measure of the total amount of energy-matter that passes through each network component (Borrett, 2013). To facilitate a comparison, all of the centrality metrics evaluated in this work, including the control analysis, are global indicators of network activity. We conducted Spearman's rank order $(\rho)$ correlation tests to compare each centrality measure to the $\overrightarrow{s c}$ results from both study sites.

All ENA calculations of control analysis and alternative centrality measures were conducted in $\mathrm{R}$ using the enaR 2.8 software package (Lau et al., 2013; Borrett and Lau, 2014). The algorithms necessary to conduct the control analyses presented in this work are now available as part of the enaR package.

\subsection{Uncertainty analysis}

The uncertainty analysis conducted in this work evaluated the robustness of the ENA results to uncertainty in the magnitude network flows. The flow values used to construct both networks were parameterized through a combination of empirical measurements, literature values, and mass balance. The uncertainty inherent in the structure of each network propagates through the analyses to result in uncertainty in the ENA results. We applied linear inverse modeling and a Monte Carlo approach to generate sets of plausible networks for each site (Kones et al., 2009). The network flux values presented in Figure11were combined with information about the uncertainty in each flux (see Hines et al., 2015) to generate sets of 10,000 plausible, balanced networks at each site. The model generation for the uncertainty analysis was conducted using the limSolve package for linear inverse modeling in R version 3.0.2 (Soetaert et al., 2009; Van den Meersche et al., 2009).

After generating the plausible model sets, we applied the control analysis from Schramski et al. (2006), as well as average eigenvector, average environ, and throughflow centrality analyses, to model sets for each site to obtain a distribution of values for the response variables in plausible networks. These distributions were used to generate $95 \%$ confidence intervals for each measure, and these confidence intervals were used to test the null hypothesis that the sites were not different. We first compared the system control $(\overrightarrow{s c})$ results between sites and used a space-for-time substitution (Pickett, 1989) to generate predictions about how seawater intrusion may alter the functioning of the estuarine $\mathrm{N}$ cycle. We then compared the system control results to the other centrality measures calculated in this study. Finally, we compared the control difference matrices $(\mathbf{C D})$ between sites to highlight key ecological relationships. 


\section{Results}

\subsection{System control comparison}

The values of the system control vector $(\overrightarrow{s c})$ for the original models at the oligohaline and polyhaline sites can be seen in Fig. 2. The sign and relative magnitude of these system control values determined the control role for each node with respect to the whole system at each site. Although in some cases there were small differences between the system control values for the nodes in the original oligohaline and polyhaline networks, these differences were not maintained in the $95 \%$ confidence intervals of plausible control values produced by the uncertainty analysis (Fig. 3). Therefore, no significant difference could be detected between the functional role of $\mathrm{N}$ cycling components at the oligohaline and polyhaline sites.

The $95 \%$ confidence intervals of plausible $\overrightarrow{s c}$ values for six of the eight network compartments contained zero (Fig. 3). Therefore, these models did not provide enough evidence to reject the null hypothesis that these compartments had control values different from zero. However, none of the plausible control values for the W-NH 4 or $\mathrm{S}_{-} \mathrm{NO}_{x}$ compartments included zero at either the of the study sites (Fig. 3). This result indicates that sediment nitrate-nitrite was a consistent controller of the $\mathrm{N}$ cycle in the CFRE, while ammonium in the water column was controlled by the rest of the components in the network.

\subsection{Centrality comparison}

The average eigenvector centrality analysis showed that the $\mathrm{NH}_{4}^{+}$and microbial $\mathrm{N}$ pools in the water column and sediment hold the most important positions in these network models. No difference in average eigenvector centrality was observed between the sites, as both networks had identical topologies. The average environ and throughflow centrality metrics, however, showed qualitatively different results from average eigenvector centrality, and suggested that a greater emphasis should be placed on the importance of organic $\mathrm{N}$ in these ecosystems (Fig. 4). The uncertainty analysis results for the average environ centrality analyses detected no significant difference in the importance of $\mathrm{N}$ cycling components at the oligohaline and polyhaline sites, while the uncertainty analysis for throughflow centrality indicated that one node, $\mathrm{W}-\mathrm{NO}_{x}$, differed in importance between the two sites, as the $95 \%$ confidence intervals of these compartments did not overlap.

A comparison of the results of the established centrality measures examined in this work with the system control results showed no clear relationship (Fig. 4. d-f). This observation was confirmed by the Spearman's $\rho$ tests from comparisons between $\overrightarrow{s c}$ and average eigenvector centrality $(\rho=-0.02, p=0.91)$, average 
environ centrality $(\rho=-0.12, p=0.66)$, and throughflow centrality $(\rho=-0.07, p=0.80)$ that revealed no significant correlations.

\subsection{Control difference comparison}

The control matrix (CD) comparison quantified the individual control relationships between each network component at each of the two sites; these matrices can be seen in Fig. 2. The CD matrices were antisymmetric due to the fact that the control relationship can be considered from the perspective of the donor and receiver nodes. Little difference was observed between the control relationships at the oligohaline and polyhaline sites, as all but one control relationship had the same sign in both networks (Fig. 5). However, at the oligohaline site sediment $\mathrm{NH}_{4}^{+}$controlled sediment $\mathrm{NO}_{x}^{-}$, while sediment $\mathrm{NO}_{x}^{-}$controlled

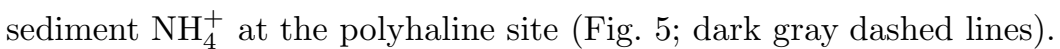

The difference in nature of the relationship between the sediment $\mathrm{NH}_{4}^{+}$and $\mathrm{NO}_{x}^{-}$compartments at the oligohaline and polyhaline sites was generally supported by the uncertainty analysis. While the $95 \%$ confidence interval for the control relationships between these two compartments at the oligohaline site (-0.022 to 0.311$)$ included zero, the confidence interval at the polyhaline site $(-0.320$ to -0.022$)$ did not, indicating that a statistically significant pattern of control could be detected. The minute overlap in the $95 \%$ confidence intervals $(<0.1 \%)$ further suggest that these compartments have different functional roles at these two sites (Fig. 6).

\section{Discussion}

Here, we first examine the importance and roles of different components in the estuarine $\mathrm{N}$ cycle at the oligohaline and polyhaline sites using the system control results. We then compare these results to the three established centrality measures examined in this study to demonstrate how system control is a different and informative form of centrality. Next, we examine the individual control relationships among the $\mathrm{N}$ cycling network components at each site to highlight differences with potential ecological importance. Finally, we highlight the conclusions of this work.

\subsection{System control and the roles of $N$ pools}

The system control value for each node calculated in the $\overrightarrow{s c}$ vector represents the relative influence of each $\mathrm{N}$ pool on the movement of $\mathrm{N}$ through all other network components (Schramski et al., 2006). In this way, the system control analysis provided a measure of which nodes are most important for regulating $\mathrm{N}$ flow in these networks, as well as the relative roles of network components. The overlapping $95 \%$ confidence 
intervals of system control values for each node comparison between the oligohaline and polyhaline networks indicated that these results did not support the hypothesis that there would be differences in which network components regulate $\mathrm{N}$ flow at these sites (Fig. 31). This finding implies that $\mathrm{N}$ cycling components have the same roles in regulating the movement of $\mathrm{N}$ throughout the estuary during the summer season, and is consistent with the findings of Schramski et al. (2007) that showed little difference in the importance of N cycling components across four summer seasons in the Neuse River Estuary, NC. It should be noted that Schramski et al. (2007) observed seasonal variation in the importance of $\mathrm{N}$ cycling components, but the significance of this variation is unclear as no uncertainty analyses were conducted.

The distribution of $\overrightarrow{s c}$ values for plausible models included zero for six of the eight nodes, therefore the current data are unable to determine if the control role of these nodes is significantly different from zero. However, the $\mathrm{S}^{-\mathrm{NO}_{x}}$ compartment was a controlling factor (positive control values), while the $\mathrm{W}-\mathrm{NH}_{4}$ compartment was controlled by the rest of the system (negative control values), in all plausible models at both sites (Fig. 3). These results are consistent with the findings of Schramski et al. (2007), who reported $\mathrm{NO}_{x}$ as an important controlling factor in the Neuse River N cycle, and may be an indication that ammonium is controlled do to the preferential assimilation of ammonium over nitrate (Zehr and Ward, 2002). Poach et al. (2003) note that denitrification can be nitrate-nitrite limited, and Trimmer et al. (2005) found that nitratenitrite concentrations regulated anammox activity in estuarine sediments, lending support to the finding that sediment nitrate-nitrate regulates the movement of $\mathrm{N}$ through the CFRE.

One possible explanation for the dominant role of nitrate-nitrite in regulating the flow of $\mathrm{N}$ is the high demand for these substrates in estuaries from both DNRA and denitrification (Aziz and Nedwell, 1986; Middelburg and Nieuwenhuize, 2000; Gruber, 2008). Alternatively, the role of ammonium may be de-emphasized in the CFRE because this is a blackwater system and lacks significant contributions from phytoplankton or benthic macroalgae (Dame et al., 2000; Mallin et al., 2010). Ammonium can serve as the dominant resource for phytoplankton in estuaries (Pennock, 1987), and thus systems without phytoplankton may exhibit enhanced control from nitrate-nitrite. Furthermore, ammonium may exert less control in estuarine ecosystems because uptake by bacteria may be less important in estuaries than in open ocean environments due to higher levels of dissolved free amino acids and nitrate (Hoch and Kirchman, 1995; Kirchman et al., 1989; Kirchman, 1994).

\subsection{System control as a measure of centrality}

Centrality measures in network science provide information about the importance and relationships between the components of a network (Freeman, 1979; Wasserman and Faust, 1994; Borgatti, 2005). These 
measures provide distinct, but often correlated (Jordán et al., 2007; Valente et al., 2008; Fann and Borrett, 2012) and sometimes redundant (Baranyi et al., 2011), information on the contribution of each component to network functioning. While these centrality metrics are the result of stead-state analysis and therefore do not directly address dynamic changes in ecosystems, the flow networks used for these analyses explicitly represent the movement of energy-matter through an ecosystem, and thus these centrality metrics provide information on an ecosystem's current state. The $\overrightarrow{s c}$ vector produced by summing the rows of the CD matrix provides a measure of the centrality for each network node that is both directional and global in nature. In this way, system control is a different type of indicator that quantifies a both the importance and role in ecosystem functioning for each network component.

Collectively, the three established centrality measures examined in this study indicated that organic $\mathrm{N}$, ammonium pools, and microbial biomass are the most important factors contributing to $\mathrm{N}$ cycling in the CFRE (Fig. 41). One possible explanation for this result is that organic $\mathrm{N}$ and ammonium serve as large contributors to the N cycling in the CFRE because both bacterial and phytoplankton activity been linked to its availability (Seitzinger and Sanders, 1997; Paerl et al., 1998). This finding implies that careful regulation of organic nutrient loading may be essential for managing the $\mathrm{N}$ cycle in the CFRE.

Although these established centrality measures provided qualitatively different results, the general agreement of throughflow, average eigenvector, and average control centralities about the importance of some compartments, such as sediment ammonium (Fig. 4), is not surprising because all of these measures generally quantify flow in the components of a network (Baranyi et al., 2011). The $\overrightarrow{s c}$ vector provides a different form of centrality because this metric quantifies the effect of each component on the rest of the network, rather than simply the amount of material moving through each component (Schramski et al., 2006, 2007). The lack of correlation between system control and any of the centrality metrics examined highlights the fact that system control is a distinct form of centrality (Fig. 4). Unlike other centrality measures, system control indicated that nitrate-nitrite in the sediment was the dominant component in regulating the movement of $\mathrm{N}$ in the CFRE networks, while the water column ammonium compartment was controlled by the rest of the system components (Fig. 3). This result is consistent with observations in both natural and constructed wetlands. For example, Middelburg and Nieuwenhuize (2000) found that nitrate-nitrite was the main form of $\mathrm{N}$ taken up by bacteria in the estuarine portion of the Thames River, UK, while Poach et al. (2003) found that denitrification was limited by nitrate-nitrite concentrations and enhanced by the addition of partially nitrified waste waters in a constructed wetland. This finding implies that policies regulating the $\mathrm{S}_{-} \mathrm{NO}_{x}$ pool may be the most effective for maintaining the current state of functionality in the $\mathrm{N}$ cycle in the CFRE 
because this node has the greatest ability influence the on other parts of this system.

\subsection{Individual control relationships}

One benefit to control analysis is the ability to apply the analysis across multiple hierarchical levels. Specifically, the values of the CD matrix are measures of the individual control relationships in a network, which can be summed to result in the $\overrightarrow{s c}$ vector. In this example, the values of CD constitute a system-wide representation of neighborhood level relationships, while the values of $\overrightarrow{s c}$ describe node level relationships (Hines and Borrett, 2014). Conducting analyses at multiple hierarchical levels is important because ecologically important features may be visible at one level, but obscured at another (Hines and Borrett, 2014).

We examined the control relationships between each pair of $\mathrm{N}$ pools in the $\mathbf{C D}$ matrices to confirm the results of the $\overrightarrow{s c}$ vectors that no statistically significant differences were present between the oligohaline and polyhaline sites. The CD matrices indicated that 27 of the 28 possible comparisons were similar in magnitude and direction between the two sites (Fig. [5), suggesting that the relationships among microbial processes that link the nutrient pools at these two sites were largely similar. For example, $\mathrm{S}-\mathrm{NH}_{4}$ and $\mathrm{S}-\mathrm{NO}_{x}$ pools exerted nearly the same amount of positive control on microbial biomass in both models, reflecting the fact that microbial organisms have the same substrate requirements at both sites, regardless of other environmental conditions (Thayer, 1974; Middelburg and Nieuwenhuize, 2000). However, the difference observed in the $\mathbf{C D}$ values for the relationship between the $\mathrm{S}_{-} \mathrm{NH}_{4}$ and $\mathrm{S}-\mathrm{NO}_{x}$ compartments suggests that ecologically important differences may exists in the $\mathrm{N}$ cycle at these two sites. This control relationship was reversed such that S-NH 4 controlled S-NO$x$ at the oligohaline site, but was controlled by $\mathrm{S}^{-\mathrm{NO}_{x}}$ at the polyhaline site. The difference in this control relationship was generally robust to the uncertainty analysis (Fig. 60), and therefore suggests that the way microbial processes link these two $\mathrm{N}$ pools may differ at these two sites.

Empirical and modeling studies show some support for the hypothesis that differences in microbial processes resulting from environmental conditions are the cause of the reversed control relationship between the S-NH 4 and $\mathrm{S}_{-} \mathrm{NO}_{x}$ compartments observed in these models. Specifically, nitrification (conversion of ammonium to nitrate-nitrite) is inhibited by the high levels of sulfide associated with more saline waters (Joye and Hollibaugh, 1995; Rysgaard et al., 1999), while DNRA (conversion of nitrate-nitrite to ammonium) may be enhanced by the same environmental conditions (Giblin et al., 2010). The reversal of control relationships observed in these models has potential ecological relevance because the transformation processes of nitrification and DNRA can provide the substrate for, and thus be coupled to, the $\mathrm{N}$ removal processes of denitrification and anammox (Jenkins and Kemp, 1984; An and Joye, 2001). Differences in 
these couplings could drive the differences in control relationship between $\mathrm{N}$ pools. Hines et al. (2015) showed that the coupling of nitrification to denitrification is greater in the oligohaline model, while DNRA coupled to anammox was greater in the polyhaline model. Therefore, the control analysis results suggest that the differences in coupling strength between these two sites may be great enough to reverse the control relationship between sediment ammonium and sediment nitrate-nitrite.

As seawater intrusion progresses, the managers of estuaries must consider how these changing environmental conditions will alter their management strategies (Bricker et al., 1999). The reversal of the control relationship between ammonium and nitrate-nitrate in the sediment at the oligohaline and polyhaline sites suggests that seawater intrusion may alter the control relationship between these two $\mathrm{N}$ pools. As a result, changes in nitrate-nitrite concentrations may have a greater effect on the amount of ammonium in the upper portion of the CFRE than is observed today.

\subsection{Conclusions}

We recognize four major contributions to network ecology and the understanding of the estuarine $\mathrm{N}$ cycle in this work. First, we present the system control vector $(\overrightarrow{s c})$ from control analysis in ENA as a measure of centrality for identifying the functionally and importance of ecosystems components. To our knowledge, this is the first presentation of system control as a centrality measure. Second, we highlight differences between system control and other three established global centrality measures. The lack of correlation between system control and any of these established measures indicates that system control provides a different perspective on network functioning. Third, we provide an example of the application of control analysis to an estuarine $\mathrm{N}$ cycle, an the interpretation of ENA results through an uncertainty analysis. Together, these analyses highlight the importance of nitrate-nitrite regulating the $\mathrm{N}$ cycle in the CFRE ecosystem. Fourth, we demonstrate that the environmental conditions associated with seawater intrusion may reverse the control relationship between ammonium and nitrate-nitrite in the sediment. This finding is important because it implies that nitrate-nitrite concentrations may become regulators of ammonium concentrations in the upper portions of estuaries as seawater intrusion progresses.

\section{Acknowledgements}

We thank Dr. John Schramski for helping us to get started using control analysis. We also thank the anonymous reviewers who helped to improve this manuscript. Funding for this work was provided by the US National Science Foundation (DEB1020944 and OCE0851435). 
An, S., Joye, S.B., 2001. Enhancement of coupled nitrification-denitrification by benthic photosynthesis in shallow estuarine sediments. Limnol. and Oceanogr. 46, 62-74.

Anderson, D.M., Glibert, P.M., Burkholder, J.M., 2002. Harmful algal blooms and eutrophication: Nutrient sources, composition, and consequences. Estuaries 25, 704-726.

Aziz, S., Nedwell, D., 1986. The nitrogen cycle of an east coast, UK saltmarsh: II. Nitrogen fixation, nitrification, denitrification, tidal exchange. Estuar. Coast. Shelf S. 22, 689-704.

Baranyi, G., Saura, S., Podani, J., Jordán, F., 2011. Contribution of habitat patches to network connectivity: Redundancy and uniqueness of topological indices. Ecol. Indic. 11, 1301-1310.

Bengtsson, J., 1998. Which species? What kind of diversity? Which ecosystem function? Some problems in studies of relations between biodiversity and ecosystem function. Appl. Soil Ecol. 10, 191-199.

Bernhard, A.E., Donn, T., Giblin, A.E., Stahl, D.A., 2005. Loss of diversity of ammonia-oxidizing bacteria correlates with increasing salinity in an estuary system. Environ. Microbiol. 7, 1289-1297.

Bernhard, A.E., Tucker, J., Giblin, A.E., Stahl, D.A., 2007. Functionally distinct communities of ammonia-oxidizing bacteria along an estuarine salinity gradient. Environ. Microbiol. 9, 1439-1447.

Boesch, D.F., 2006. Scientific requirements for ecosystem-based management in the restoration of Chesapeake Bay and coastal Louisiana. Ecol. Eng. 26, 6-26.

Bonacich, P., 1972. Factoring and weighting approaches to clique identification. J. Math. Soc. 2, 113-120.

Bonacich, P., 1987. Power and centrality: A family of measures. Am. J. Sociol. 92, 1170-1182.

Bonacich, P., 2007. Some unique properties of eigenvector centrality. Soc. Networks 29, 555-564.

Borgatti, S.P., 2005. Centrality and network flow. Soc. Networks 27, 55-71.

Borgatti, S.P., Everett, M.G., 2006. A graph-theoretic perspective on centrality. Soc. Networks 28, $466-484$.

Borrett, S.R., 2013. Throughflow centrality is a global indicator of the functional importance of species in ecosystems. Ecol. Indic. 32, 182-196.

Borrett, S.R., Lau, M.K., 2014. enaR: An R package for Ecosystem Network Analysis. Methods Ecol. Evol. 5, $1206-1213$.

Borrett, S.R., Moody, J., Edelmann, A., 2014. The rise of Network Ecology: Maps of the topic diversity and scientific collaboration. Ecol. Model. 293, 111-127.

Boynton, W.R., Hagy, J.D., Cornwell, J.C., Kemp, W.M., Greene, S., Owens, M., Baker, J.E., Larsen, R.K., 2008. Nutrient budgets and management actions in the patuxent river estuary, maryland. Estuar. Coast. 31, 623-651.

Boynton, W.R., Kemp, W.M., 2008. Nitrogen in the marine environment. Chapter 18: Estuaries. pp. 809-856.

Bricker, S., Clement, C., Pirhalla, D., Orlando, S., Farrow, D., 1999. National Estuarine Eutrophication Assessment: Effects of nutrient enrichment in the nation's estuaries. Technical Report. NOAA.

Burkholder, J.M., Mallin, M.A., Glasgow, H.B., Larsen, L.M., McIver, M.R., Shank, G.C., Deamer-Melia, N., Briley, D.S., Springer, J., Touchette, B.W., et al., 1997. Impacts to a coastal river and estuary from rupture of a large swine waste holding lagoon. J. Environ. Qual. 26, 1451-1466.

Cabrita, M.T., Catarino, F., Slawyk, G., 1999. Interactions of light, temperature and inorganic nitrogen in controlling planktonic nitrogen utilisation in the Tagus Estuary. Aquat. Ecol. 33, 251-261.

Canfield, D.E., Glazer, A.N., Falkowski, P.G., 2010. The evolution and future of Earth's nitrogen cycle. Science 330, $192-196$.

Caraco, N., Lampman, G., Cole, J., Limburg, K., Pace, M., Fischer, D., 1998. Microbial assimilation of DIN in a nitrogen rich estuary: Implications for food quality and isotope studies. Mar. Ecol. Prog. Ser. 167, 59-71. 
Christensen, N.L., Bartuska, A.M., Brown, J.H., Carpenter, S., D'Antonio, C., Francis, R., Franklin, J.F., MacMahon, J.A., Noss, R.F., Parsons, D.J., Peterson, C.H., Turner, M.G., Woodmansee, R.G., 1996. The report of the Ecological Society of America committee on the scientific basis for ecosystem management. Ecol. Appl. 6, 665-691.

Cloern, J.E., 2001. Our evolving conceptual model of the coastal eutrophication problem. Mar. Ecol. Prog. Ser. 210, 223-253.

Codd, G.A., 2000. Cyanobacterial toxins, the perception of water quality, and the prioritisation of eutrophication control. Ecol. Eng. 16, 51-60.

Costanza, R., d'Arge, R., de Groot, R., Farber, S., Grasso, M., Hannon, B., Limburg, K., Naeem, S., O'Neill, R.V., Paruelo, J., Raskin, R.G., Sutton, P., van den Belt, M., 1997. The value of the world's ecosystem services and natural capital. Nature $387,253-260$.

Crowder, L., Norse, E., 2008. Essential ecological insights for marine ecosystem-based management and marine spatial planning. Mar. Policy 32, 772-778.

Dame, R., Alber, M., Allen, D., Mallin, M., Montague, C., Lewitus, A., Chalmers, A., Gardner, R., Gilman, C., Kjerfve, B., Pinckney, J., Smith, N., 2000. Estuaries of the south Atlantic coast of North America: Their geographical signatures. Estuaries 23, 793-819.

Day, J.W., Barras, J., Clairain, E., Johnston, J., Justic, D., Kemp, G.P., Ko, J.Y., Lane, R., Mitsch, W.J., Steyer, G., Templet, P., Yañez-Arancibia, A., 2005. Implications of global climatic change and energy cost and availability for the restoration of the Mississippi Delta. Ecol. Eng. 24, 253-265.

Ehrlich, P.R., Mooney, H.A., 1983. Extinction, substitution, and ecosystem services. BioScience 33, $248-254$.

Estrada, E., 2007. Characterization of topological keystone species: Local, global and "meso-scale" centralities in food webs. Ecol. Complex. 4, 48-57.

Estrada, E., 2010. Generalized walks-based centrality measures for complex biological networks. J. Theor. Biol. 263,556 - 565.

Estrada, E., Bodin, O., 2008. Using network centrality measures to managae landscape connectivity. Ecol. Appl. 18, 1810-1825.

Fann, S.L., Borrett, S.R., 2012. Environ centrality reveals the tendency of indirect effects to homogenize the functional importance of species in ecosystems. J. Theor. Biol. 294, 74-86.

Fath, B.D., 2004. Distributed control in ecological networks. Ecol. Model. 179, 235-245.

Fath, B.D., Patten, B.C., 1999. Review of the foundations of network environ analysis. Ecosystems 2, $167-179$.

Fath, B.D., Scharler, U.M., Ulanowicz, R.E., Hannon, B., 2007. Ecological network analysis: Network construction. Ecol. Model. 208, 49-55.

Fisher, T.R., Harding, L.W., Stanley, D.W., Ward, L.G., 1988. Phytoplankton, nutrients, and turbidity in the Chesapeake, Delaware, and Hudson estuaries. Estuar. Coast. Shelf S. 27, 61-93.

Freeman, L.C., 1979. Centrality in networks. I. Conceptual clarificaiton. Soc. Networks 1, $215-239$.

Giblin, A.E., Tobias, C.R., Song, B., Weston, N., Banta, G.T., Rivera-Monroy, V.H., 2013. The importance of dissimilatory nitrate reduction to ammonium (DNRA) in the nitrogen cycle of coastal ecosystems. Oceanography 26, $124-131$.

Giblin, A.E., Weston, N.B., Banta, G.T., Tucker, J., Hopkinson, C.S., 2010. The effects of salinity on nitrogen losses from an oligohaline estuarine sediment. Estuar. Coast. 33, 1054-1068.

Gruber, N., 2008. Nitrogen in the marine environment. Chapter 1 The marine nitrogen cycle: Overview and challenges. pp. $1-50$.

Hackney, C.T., Yelverton, G.F., 1990. Effects of human activities and sea level rise on wetland ecosystems in the Cape Fear River Estuary, North Carolina, USA, in: Wetland Ecology and Management: Case Studies. Springer, pp. 55-61. 
Hannon, B., 1973. The structure of ecosystems. J. Theor. Biol. 41, 535-546.

Hines, D.E., Borrett, S.R., 2014. A comparison of network, neighborhood, and node levels of analyses in two models of nitrogen cycling in the Cape Fear River Estuary. Ecol. Model. 293, 210-220.

Hines, D.E., Lisa, J.A., Song, B., Tobias, C.R., Borrett, S.R., 2012. A network model shows the importance of coupled processes in the microbial N cycle in the Cape Fear River Estuary. Estuar. Coast. Shelf S. 106, 45-57.

Hines, D.E., Lisa, J.A., Song, B., Tobias, C.R., Borrett, S.R., 2015. Estimating the effects of seawater intrusion on an estuarine nitrogen cycle by comparative network analysis. Mar. Ecol. Prog. Ser. 524, 137-154.

Hoch, M.P., Kirchman, D.L., 1995. Ammonium uptake by heterotrophic bacteria in the Delaware Estuary and adjacent coastal waters. Limnol. Oceanogr. 40, 886-897.

Hooper, D.U., Chapin III, F., Ewel, J., Hector, A., Inchausti, P., Lavorel, S., Lawton, J., Lodge, D., Loreau, M., Naeem, S., Schmid, B., Setälä, H., Symstad, A., Vandermeer, J., Wardle, D., 2005. Effects of biodiversity on ecosystem functioning: A consensus of current knowledge. Ecol. Monogr. 75, 3-35.

Howarth, R.W., Marino, R., 2006. Nitrogen as the limiting nutrient for eutrophication in coastal marine ecosystems: Evolving views over three decades. Limnol. and Oceanogr. 51, 364-376.

Howarth, R.W., Marino, R., Cole, J.J., et al., 1988. Nitrogen fixation in freshwater, estuarine, and marine ecosystems. 2. Biogeochemical controls. Limnol. and Oceanogr. 33, 688-701.

Jang, D., Hwang, J.H., Park, Y.G., Park, S.H., 2012. A study on salt wedge and river plume in the Seom-Jin river and estuary. KSCE J. Civ. Eng. 16, 676-688.

Jenkins, M., Kemp, W., 1984. The coupling of nitrification and denitrification in two estuarine sediments. Limnol. Oceanogr. 29, 609-619.

Jordán, F., Benedek, Z., Podani, J., 2007. Quantifying positional importance in food webs: A comparison of centrality indices. Ecol. Model. 205, 270-275.

Jordán, F., Liu, W.C., Davis, A.J., 2006. Topological keystone species: Measures of positional importance in food webs. Oikos $112,535-546$.

Joye, S.B., Anderson, I.C., 2008. Nitrogen in the Marine Environment. 2nd ed.. Elsevier. Nitrogen cycling in coastal sediments. pp. $867-915$.

Joye, S.B., Hollibaugh, J.T., 1995. Influence of sulfide inhibition of nitrification on nitrogen regeneration in sediments. Science $270,623-625$.

Kemp, W., Boynton, W., Adolf, J., Boesch, D., Boicourt, W., Brush, G., Cornwell, J., Fisher, T., Glibert, P., Hagy, J., et al., 2005. Eutrophication of Chesapeake Bay: Historical trends and ecological interactions. Mar. Ecol. Prog. Ser. 303 , 1-29.

Kirchman, D., 1994. The uptake of inorganic nutrients by heterotrophic bacteria. Microb. Ecol. 28, 255-271.

Kirchman, D.L., Keil, R.G., Wheeler, P.A., 1989. The effect of amino acids on ammonium utilization and regeneration by heterotrophic bacteria in the subarctic pacific. Deep Sea Res. 36, 1763-1776.

Kones, J.K., Soetaert, K., van Oevelen, D., Owino, J.O., 2009. Are network indices robust indicators of food web functioning? A monte carlo approach. Ecol. Model. 220, 370-382.

Kremen, C., 2005. Managing ecosystem services: What do we need to know about their ecology? Ecol. Lett. 8, $468-479$.

Lau, M.K., Borrett, S.R., Hines, D.E., 2013. enaR: Tools ecological network analysis. R package version 2.0.

Levin, S.A., Lubchenco, J., 2008. Resilience, robustness, and marine ecosystem-based management. BioScience 58, $27-32$.

Mallin, M.A., McIver, M.R., Merrit, J.F., 2009. Environmental assessment of the lower Cape Fear River system, 2008. Technical 
Report 09-06. University of North Carolina Wilmington.

Mallin, M.A., McIver, M.R., Merrit, J.F., 2010. Environmental assessment of the lower Cape Fear River system, 2009. Technical Report 10-04. University of North Carolina Wilmington.

Middelburg, J.J., Nieuwenhuize, J., 2000. Nitrogen uptake by heterotrophic bacteria and phytoplankton in the nitrate-rich thames estuary. Mar. Ecol. Prog. Ser. 203.

Mills, L.S., Soulé, M.E., Doak, D.F., 1993. The keystone-species concept in ecology and conservation. BioScience , $219-224$.

Nixon, S.W., 1995. Coastal marine eutrophication: A definition, social causes, and future concerns. Ophelia 41, $199-219$.

Paerl, H.W., 2006. Assessing and managing nutrient-enhanced eutrophication in estuarine and coastal waters: Interactive effects of human and climatic perturbations. Ecol. Eng. 26, 40-54.

Paerl, H.W., Pinckney, J.L., Fear, J.M., Peierls, B.L., 1998. Ecosystem responses to internal and watershed organic matter loading: Consequences for hypoxia in the eutrophying Neuse River Estuary, North Carolina, USA. Mar. Ecol. Prog. Ser. $166,17$.

Patten, B.C., 1982. Environs: Relativistic elementary particles for ecology. Am. Nat. 119, $179-219$.

Patten, B.C., 2013. Systems ecology and environmentalism: Getting the science right. Ecol. Eng. 61, 446-455.

Patten, B.C., Auble, G.T., 1981. System theory of the ecological niche. Am. Nat. 117, 893-922.

Pennock, J.R., 1987. Temporal and spatial variability in phytoplankton ammonium and nitrate uptake in the Delaware Estuary. Estuar. Coast. Shelf S. 24, 841-857.

Pickett, S.T., 1989. Space-for-time substitution as an alternative to long-term studies, In: Long-term Studies in Ecology. Springer, pp. 110-135.

Poach, M., Hunt, P., Vanotti, M., Stone, K., Matheny, T., Johnson, M., Sadler, E., 2003. Improved nitrogen treatment by constructed wetlands receiving partially nitrified liquid swine manure. Ecol. Eng. 20, 183-197.

Revsbech, N.P., Jacobsen, J.P., Nielsen, L.P., 2005. Nitrogen transformations in microenvironments of river beds and riparian zones. Ecol. Eng. 24, 447-455.

Rudek, J., Paerl, H.W., Mallin, M.A., Bates, P.W., 1991. Seasonal and hydrological control of phytoplankton nutrient limitation in the lower Neuse River Estuary, North Carolina. Mar. Ecol. Prog. Ser. 75, 133-142.

Rysgaard, S., Thastum, P., Dalsgaard, T., B., C.P., Sloth, N.P., 1999. Effects of salinity on NH ${ }_{4}^{+}$adsorption, nitrification, and denitrification in Danish estuarine sediments. Estuaries 22, 21-30.

Ryther, J.H., Dunstan, W.M., 1971. Nitrogen, phosphorus, and eutrophication in the coastal marine environment. Science $171,1008-1013$.

Santoro, A.E., 2010. Microbial nitrogen cycling at the saltwater-freshwater interface. Hydrogeol. J. 18, $187-202$.

Schramski, J.R., Gattie, D.K., Patten, B.C., Borrett, S.R., Fath, B.D., Thomas, C.R., Whipple, S.J., 2006. Indirect effects and distributed control in ecosystems: Distributed control in the environ networks of a seven-compartment model of nitrogen flow in the Neuse River Estuary, USA — steady-state analysis. Ecol. Model. 194, 189-201.

Schramski, J.R., Gattie, D.K., Patten, B.C., Borrett, S.R., Fath, B.D., Whipple, S.J., 2007. Indirect effects and distributed control in ecosystems: Distributed control in the environ networks of a seven-compartment model of nitrogen flow in the Neuse River Estuary, USA — time series analysis. Ecol. Model. 206, 18-30.

Schramski, J.R., Kazanci, C., Tollner, E.W., 2011. Network environ theory, simulation and Econet(C) 2.0. Environ. Model. Softw. 26, 419-428.

Seitzinger, S., Sanders, R., 1997. Contribution of dissolved organic nitrogen from rivers to estuarine eutrophication. Mar. Ecol. 
Prog. Ser. 159, 12.

Soetaert, K., Van den Meersche, K., van Oevelen, D., 2009. limSolve: Solving linear inverse models. R package version 1.5.1. Sutherland, W.J., Armstrong-Brown, S., Armsworth, P.R., Brereton, T., Brickland, J., Campbell, C.D., Chamberlain, D.E., Cooke, A.I., Dulvy, N.K., Dusic, N.R., Fitton, M., Freckleton, R.P., Godfray, H.C.J., Grout, N., Harvey, H.J., Hedley, C., Hopkins, J.J., B, K.N., Kirby, J., Kunin, W.E., MacDonald, D.W., Marker, B., Naura, M., Neale, A.R., 2006. The identification of 100 ecological questions of high policy relevance in the UK. J. Appl. Ecol. 43, 617-627.

Thayer, G.W., 1974. Identity and regulation of nutrients limiting phytoplankton production in the shallow estuaries near Beaufort, NC. Oecologia 14, 75-92.

Thom, R.M., 1997. System-development matrix for adaptive management of coastal ecosystem restoration projects. Ecol. Eng. $8,219-232$.

Trimmer, M., Nicholls, J.C., Morley, N., Davies, C.A., Aldridge, J., 2005. Biphasic behavior of anammox regulated by nitrite and nitrate in an estuarine sediment. Appl. Environ. Microb. 71, 1923-1930.

Ulanowicz, R.E., 2004. Quantitative methods for ecological network analysis. Comput. Biol. Chem. 28, 321-339.

Valente, T.W., Coronges, K., Lakon, C., Costenbader, E., 2008. How correlated are network centrality measures? Connections $22,16-26$.

Van den Meersche, K., Soetaert, K., Van Oevelen, D., 2009. xsample(): An R function for sampling linear inverse problems. J. Stat. Softw. 30, HASH-0x57696b8.

Walker, B.H., 1992. Biodiversity and ecological redundancy. Conserv. Biol. 6, 18-23.

Wasserman, S., Faust, K., 1994. Social network analysis: Methods and applications. Cambridge University Press, Cambridge; New York.

Whitall, D., Castro, M., Driscoll, C., 2004. Evaluation of management strategies for reducing nitrogen loadings to four US estuaries. Sci. Total Environ. 333, 25-36.

Zedler, J.B., Kercher, S., 2005. Wetland resources: Status, trends, ecosystem services, and restorability. Annu. Rev. Environ. Resour. 30, 39-74.

Zehr, J.P., Ward, B.B., 2002. Nitrogen cycling in the ocean: New perspectives on processes and paradigms. Appl. Environ. Microb. 68, 1015-1024.

Zhang, Z., Cui, B., Ou, B., Fan, X., 2012. Wetland network design for mitigation of saltwater intrusion by transferring tidal discharge. CLEAN-Soil Air Water 40, 1057-1063. 

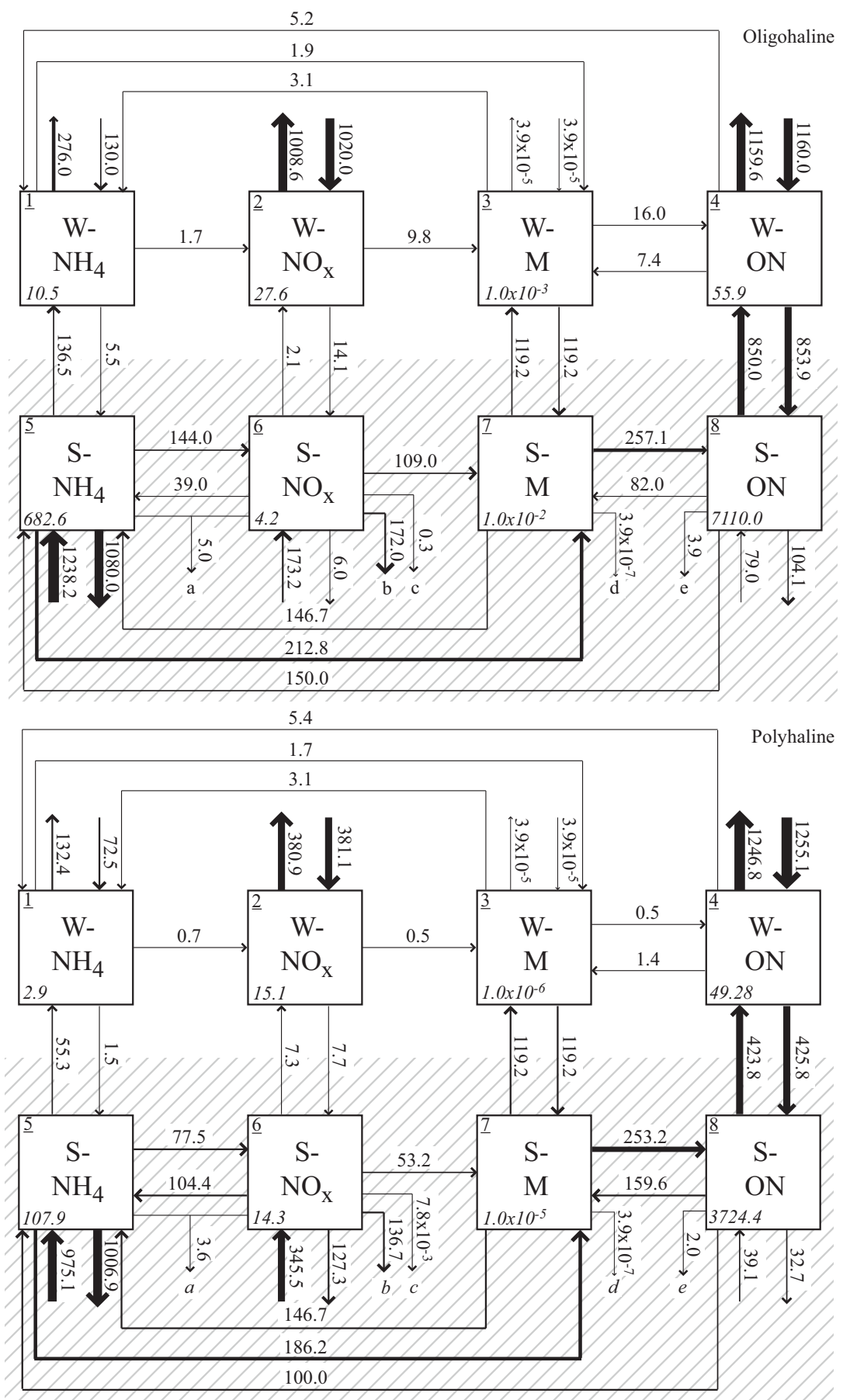

Figure 1: Network models for the nitrogen cycle at the oligohaline and the polyhaline sites in the CFRE. Each network is parameterized for the average summer day in 2008 and 2009 in units of nmol N cm$~_{-3} \mathrm{~d}^{-1}$. Hashed areas represent sediments, while unshaded areas represent the water column. Underlined numbers in nodes represent node number and order in the network matrices, and italicized numbers in nodes represent component storage. Notice that network topology is identical between the two networks to facilitate comparison between the sites. Figure modified from Hines et al. (2015). 


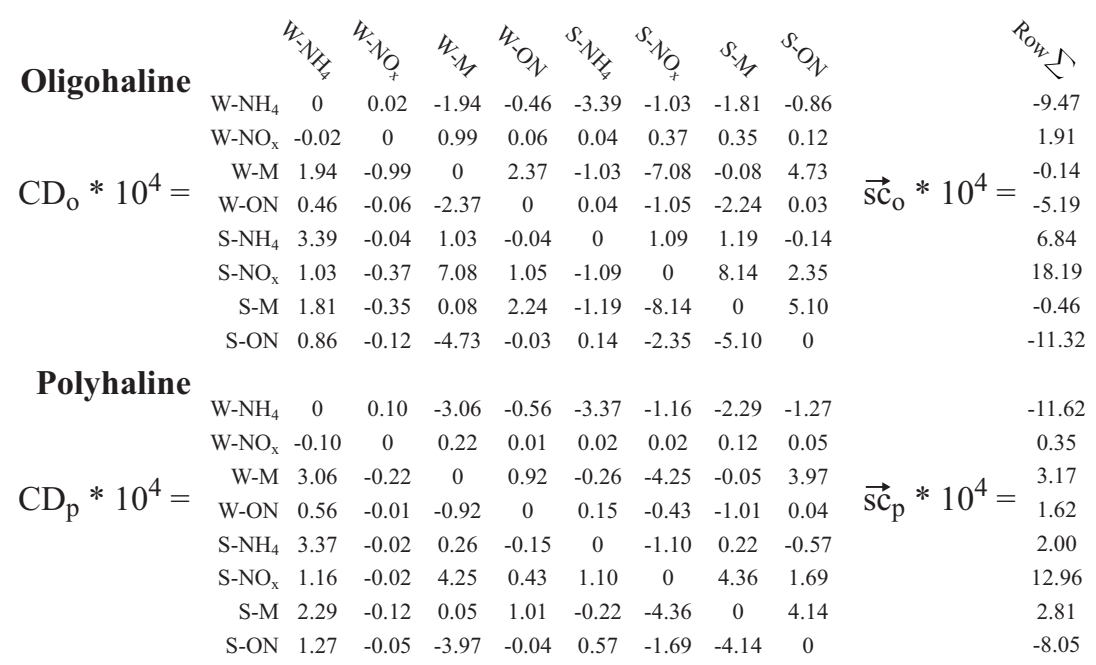

Figure 2: Control difference matrices (CD) and system control vectors $(\overrightarrow{s c})$ for the oligohaline $(\mathrm{o})$ and polyhaline $(\mathrm{p})$ networks. CD matrices show the control relationship between any two components of the network such that positive numbers indicate that the row node controls the column node and negative numbers indicate that column node controls the row node. The $\overrightarrow{s c}$ vectors are the row sums of the CD matrices, and as such represent the control exerted by the node on the system as a whole (positive) or on a node by the whole system (negative). Note that the row to column orientation in these matrices is opposite to the column to row orientation used in other control analyses such as Schramski et al. (2006). Values shown are in units of $\mathrm{nmol}^{-1} \mathrm{~cm}^{3} \mathrm{~d}$. 


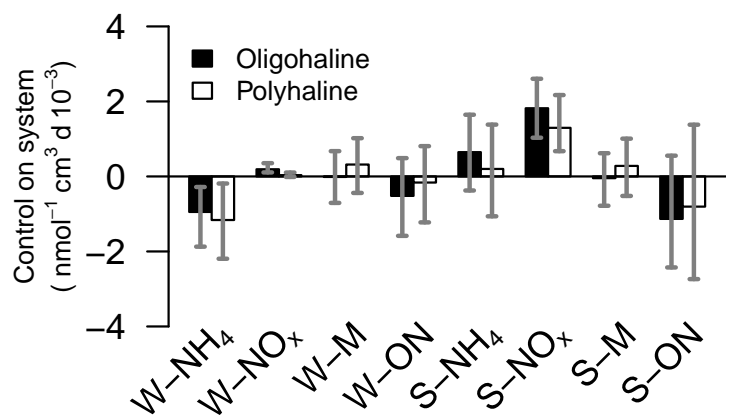

Figure 3: Comparison of SC vectors $(\overrightarrow{s c})$ for the oligohaline (black) and polyhaline (white) networks. Gray error bars show $95 \%$ distribution of system control values for the 10,000 plausible models produced by the uncertainty analysis for each site. Positive values indicate that a component exerts control on the system, while negative values indicate that this component is controlled by the system. Note that all values have have been multiplied by $10^{3}$. 

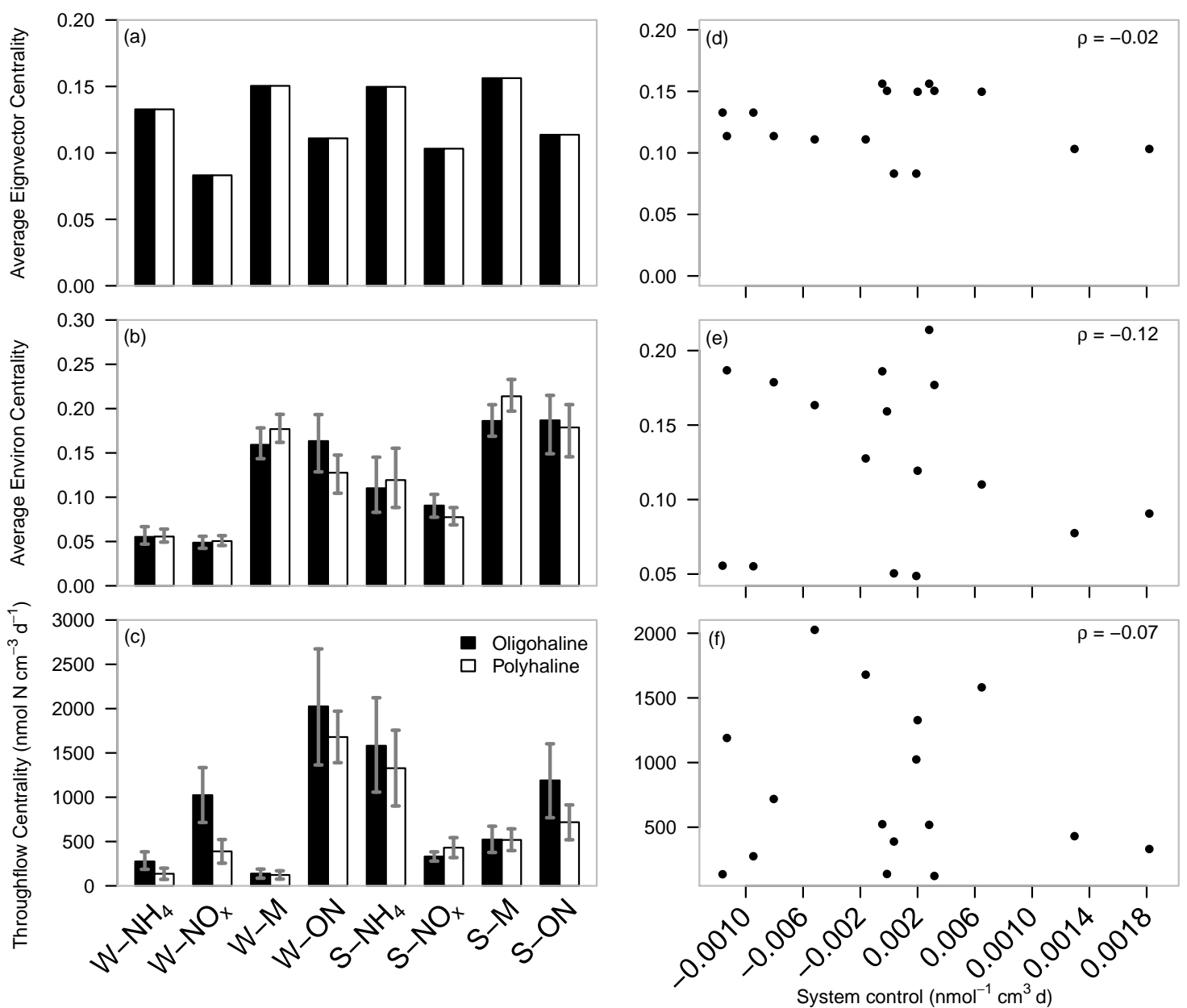

Figure 4: Three centrality measures for the CFRE N networks: (a) eigenvector centrality of the adjacency matrix, (b) average environ centrality, and (c) throughflow centrality at the oligohaline (black) and polyhaline (white) sites. Gray error bars in the bar plots show the $95 \%$ confidence interval of each centrality measure produced by the uncertainty analysis. No error bars are shown for eigenvector centrality (a) because the network structure was constant throughout the uncertainty analysis. Scatter plots to the right of each bar plot (d, e, and f) compare each centrality measure to the system control vectors $(\overrightarrow{s c})$ computed in this study. $\rho$ values indicate results of Spearmans' rank order correlation tests, which showed no significant relationship between $\overrightarrow{s c}$ and any of the other centrality measures. 
Oligohaline

(a)

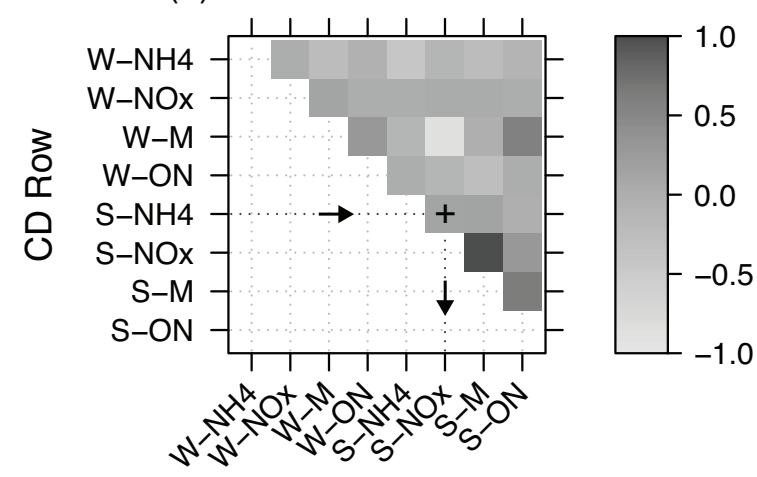

CD Column
Polyhaline

(b)

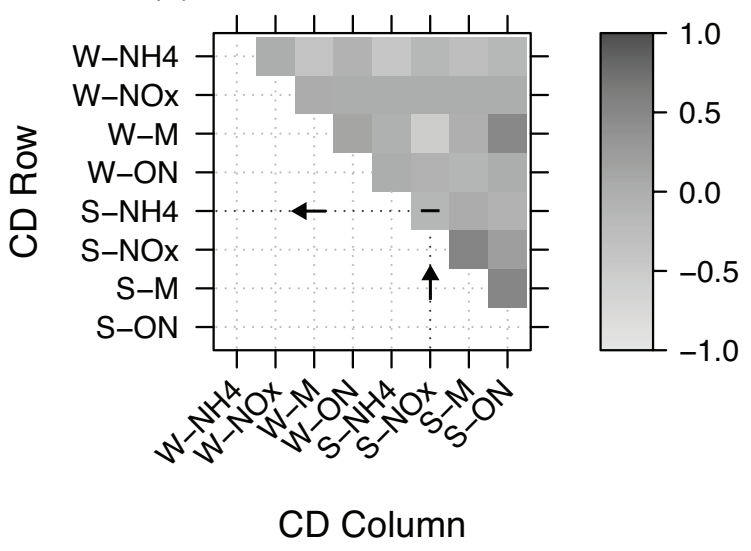

Figure 5: Heat map of the upper half of the control difference (CD) matrix for the (a) oligohaline and (b) polyhaline sites. Only the upper half of each matrix is shown because these matrices are antisymmetric. The CD matrix shows the control of each system component on every other system component. Values are normalized to the absolute value of the maximum of both CD matrices, and therefore range from negative one to one. Darker colors (positive) indicate that the row component controls the column component, while lighter colors (negative) indicate that the column component controls the row component. The gray dotted lines highlight individual node comparisons, and the + and - symbols highlight sign differences in non-node relationships between the two sites. 


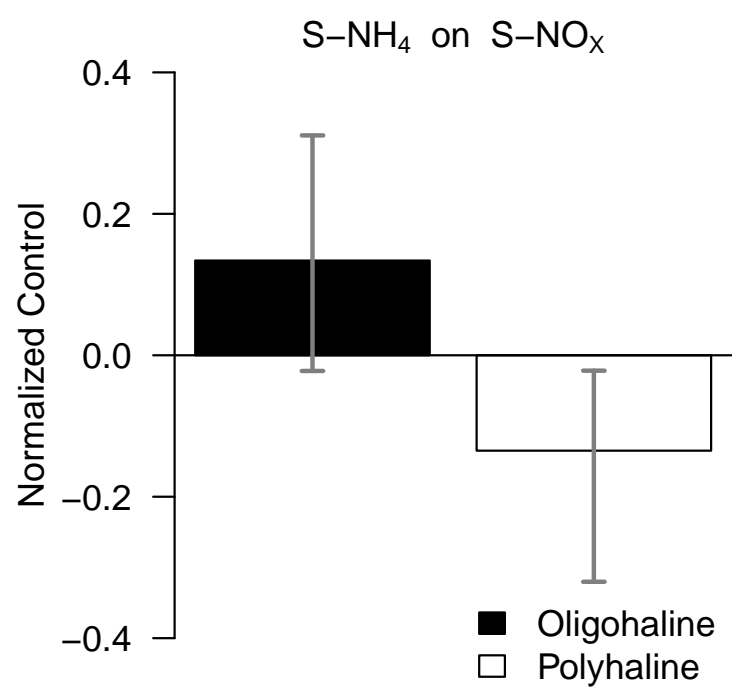

Figure 6: Bar plot showing the magnitudes of the control relationships between sediment ammonium $\left(\mathrm{S}-\mathrm{NH}_{4}\right)$ and sediment nitrate-nitrite $\left(\mathrm{S}_{-} \mathrm{NO}_{X}\right)$ at the oligohaline (black) and polyhaline (white) sites. Gray error bars show the $95 \%$ range of the respective $\mathbf{C D}$ values in the uncertainty analysis model sets. The error bars overlap by $0.1 \%$ of the range of values for the oligohaline network. 